\title{
Development of an Early Activation Hip Fracture Care Bundle and Implementation Strategy to Improve Adherence to the National Hip Fracture Clinical Care Standard
}

\author{
Kate Curtis (iD ${ }^{\mathrm{I}-4}$ \\ Peter Moules ${ }^{2}$ \\ John McKenzie ${ }^{2,3}$ \\ Lauren Weidl ${ }^{2}$ \\ Tanya Selak iD ${ }^{2}$ \\ Simon Binks ${ }^{2}$ \\ Daniel Hernandez ${ }^{2}$ \\ Joshua Rijsdijk ${ }^{2}$ \\ Dante Risi ${ }^{2}$ \\ James Wright ${ }^{5}$ \\ Lauren O'Rourke ${ }^{2}$ \\ Myles Knapman ${ }^{6}$ \\ Meagan Ristevski ${ }^{2}$ \\ Teala Stephens ${ }^{2}$ \\ Ian Harris ${ }^{7}$ \\ Jacqueline CT Close Cl,9 $^{8,9}$ \\ 'Susan Wakil School of Nursing and \\ Midwifery, Faculty of Medicine and \\ Health, The University of Sydney, Sydney, \\ NSW, Australia; ${ }^{2}$ Illawarra Shoalhaven \\ LHD, Emergency Department, \\ Wollongong, NSW, Australia; ${ }^{3}$ Illawarra \\ Health and Medical Research Institute, \\ Wollongong, NSW, Australia; ${ }^{4}$ George \\ Institute for Global Health, Newtown, \\ NSW, Australia; ${ }^{5}$ Agency for Clinical \\ Innovation, St Leonards, NSW, Australia; \\ ${ }^{6}$ Western NSW LHD, Department of \\ Surgery, Dubbo, NSW, Australia; ${ }^{7}$ Ingham \\ Institute of Applied Medical Research, \\ South Western Sydney Clinical School, \\ UNSW, Sydney, NSW, Australia; ${ }^{8}$ Prince \\ Wales Clinical School, UNSW, Sydney, \\ NSW, Australia; ${ }^{9}$ Neuroscience Research \\ Australia, UNSW, Sydney, NSW, Australia
}

Correspondence: Kate Curtis

Email kate.curtis@sydney.edu.au
Objective: To develop and implement a multidisciplinary early activation mechanism and bundle of care (eHIP) to improve adherence to ACSQHC standards in a regional trauma centre. Methods: Barriers to implementation were categorised using the Theoretical Domains Framework, then linked to specific strategies guided by the Behaviour Change Wheel and Behaviour Change Technique Taxonomy (BCTT). The resulting implementation strategies were assessed using Affordable, Practical, Effective, Acceptable, had Side-effects (APEASE) criteria.

Results: Eighty-three barriers to implementation of the hip fracture care bundle were identified. The behaviour change wheel process resulted in the identification of 41 techniques to address these barriers. The predominant mechanisms to achieve this were development and implementation of 1) formal policy that outlines eHIP roles; 2) video promotion; 3) pager group; 4) fascia iliaca block enabling; 5) eMR modifications; 6) face-to-face reinforcement and modelling; 7) communication and prompts; 8) environmental restructuring.

Conclusion: We applied behaviour change theory through a pragmatic evidence-based process. This resulted in a codesigned strategy to overcome staff and organisational barriers to the implementation of a multidisciplinary early activation mechanism and bundle of care (eHIP). Future work will include evaluation of the uptake and clinical impact of the care bundle.

Keywords: hip fracture, implementation, clinical pathway, emergency, behaviour change, injury, older persons, orthopaedic

\section{Introduction}

Hip fracture is the most serious and costly fall-related injury suffered by frail older people and numbers are on the rise. The human cost of a hip fracture is high; ${ }^{1} 25 \%$ of patients are dead at one year, $50 \%$ do not regain their previous level of function, and for $11 \%$ of patients, the fracture heralds the end of independent living. ${ }^{2,3}$ Hip fractures are one of the top three causes of emergency admissions involving surgery in Australia, ${ }^{4}$ with nearly 17,000 treated in Australian hospitals each year at a cost of nearly AU\$1Billion. ${ }^{5}$ An acute hip fracture results in pain, bleeding and immobility. These factors initiate inflammatory, hypercoagulable, catabolic and stress states that precipitate complications. ${ }^{6}$

Several countries have national guidelines and monitoring of outcomes for Hip Fracture management. ${ }^{7-10}$ In Australia, the Australian Commission on Safety and Quality in Health Care (ACSQHC) produced the Hip Fracture Care Clinical Care 
Standard in $2016,{ }^{11}$ consolidating the best available evidence for managing this patient group. However, there is mounting evidence of variation in the quality and safety of care of patients with hip fractures across jurisdictions and hospitals in Australia including a large amount of variation in mortality that may be explained by different approaches to delivery of care $^{12}$ For example, $61 \%$ of Australian patients and $58 \%$ of New Zealand patients with hip fractures underwent pain assessment within 30 minutes of ED arrival; $^{12} 79 \%$ of Australian patients and $67 \%$ of New Zealand patients received the gold standard femoral nerve block; $80 \%$ of Australian patients and $84 \%$ of New Zealand patients received operative intervention within 48 hours; and only $26 \%$ of Australian patients and $23 \%$ of New Zealand patients were routinely provided individualised written information on prevention of future falls and fractures. These variances are reflected around the globe f,13-18 $^{\text {. }}$

Healthcare organizations are complex social entities. ${ }^{19}$ There is a need for effective and sustainable interventions to support sustained Hip Fracture guideline uptake, $^{12}$ in particular, to ensure staff have the capability, opportunity and motivation to comply. Numerous studies have implemented best practice pathways, some demonstrating no improvement to patient outcomes ${ }^{7}$ and their uptake poor. Despite this, most published intervention studies have led to some improved outcomes for patients in targeted areas. For example, the "Hip Attack" model which, through early medical clearance, reduced time to operative intervention and post-operative complications, ${ }^{6}$ including a significant reduction in the incidence of delirium, as did that of Chuan et al. ${ }^{13}$ The implementation of a hip fracture coordination service in Israel resulted in improved osteoporotic medical treatment ${ }^{9}$ The majority of the guideline implementation evaluation reports do not comment in detail in the design and method of implementation of the pathways, compliance or uptake. Further, evidence-based clinician enabling strategies that activate the necessary referrals and care throughout the entire course of hip fracture care are required.

To improve compliance with the ACSQHC Hip Fracture Care Clinical Care Standard in our hospital, in October 2018, the Wollongong Hospital hip fracture committee designed eHIP - a multidisciplinary early activation mechanism and bundle of care. This paper describes the development and implementation of eHIP.

\section{Methods}

This project was conducted at Wollongong Hospital (WH), which manages around 350 patients with hip fractures annually. WH is consistently one of the worst performing hospitals in Australia and New Zealand for emergency department (ED) length of stay (LOS) $)^{12,20,21}$ and had previously been among the worst performing regarding time to hip fracture surgery. ${ }^{20,21}$ The process of developing of eHIP for effective implementation and maximum uptake is described, followed by the steps taken to develop an implementation plan using behaviour change theory. As this is a description of the development of an intervention, rather than an evaluation of an intervention, no ethical approval was required.

\section{Behaviour Change Theory}

The implementation plan for eHIP focuses on clinician behaviour change, with particular consideration to organisational barriers to change. Although healthcare disciplines share the same goal of improving patient outcomes, they often have differing priorities, roles, and expectations about how care should be delivered. ${ }^{22}$ Central to sustained compliance with any intervention is individual and collective human behaviour. ${ }^{22}$ As such, part of the implementation plan development, a behavioural analysis was conducted at the study sites that considered all disciplines using the following steps recommended by French et al which are known to be effective, practical and pragmatic: ${ }^{23}$. Who needs to do what, differently? 2. Using a theoretical framework, which barriers and enablers need to be addressed? 3. Which intervention components (behaviour change techniques and mode(s) of delivery) could overcome the modifiable barriers and enhance the enablers? 4. How can behaviour change be measured and understood?

\section{Step I: Development of eHIP}

eHIP is an implementation strategy that contains mechanisms to embed the ACSQHC Hip Fracture Care Clinical Care Standard in everyday clinical practice. This was a collaborative endeavour, which involved key stakeholder groups (clinicians, managers, NSW Agency for Clinical Innovation [ACI] and consumers), including the Local Health District Executive. The success of implementing practice change is heavily reliant on senior clinician support, ${ }^{24}$ those that will be impacted by the intervention, and those that will be required to act on the intervention 
(the end users). As such, a working group was formed to review each component of the ACSQHC Hip Fracture Care Clinical Standard to determine a mechanism to action each component. The multidisciplinary working group represented the key stakeholders for each discipline within the hospital that was required to contribute to ensure all components of the ACSQHC Hip Fracture Care Clinical Standard were addressed. The group was chaired by the Clinical Nurse Consultant for Surgery and comprised an emergency nurse, orthopaedic nurse manager, orthopaedic clinical educator, health service manager, geriatrician, anaesthetist, pain service (anaesthetics/nurse), orthopaedic physiotherapist, dietitian and orthopaedic surgeon and met monthly for 12 months.

\section{Step 2: Identification of Barriers to Implementation}

Throughout the 12 months, local barriers to compliance with each of the ACSQHC Hip Fracture Care Clinical Care Standard were regularly collected through a series of departmental meetings. The representative from each discipline discussed the role of their department in eHIP with their frontline clinicians and managers and assembled the feedback. Throughout this iterative consultation process, they specifically asked their colleagues about what they thought would and would not be feasible, practical, or effective. The feedback from each department was tabled at each meeting and collated in a list.

\section{Step 3: Categorising Barriers to the Theoretical Domains Framework}

The collated list of identified barriers to the implementation of eHIP was then categorised using the Theoretical Domains Framework (TDF). ${ }^{22}$ The TDF is a robustly developed tool informed by 33 theories of behaviour and behaviour change. ${ }^{22}$ These have been clustered into 14 domains, which provide a theoretical lens to view the impact of cognitive, social and environmental influences on behaviour (Table 1).

\section{Step 4: Development of Implementation Strategies}

Firstly, the barriers were mapped to intervention functions and behaviour change techniques known to be effective and guided by the Behaviour Change Wheel. ${ }^{25}$ Intervention functions are "broad categories by means of which an intervention can change behaviour". 25 Each intervention function was assessed to see if they were Affordable, Practical, Effective, Acceptable, had Sideeffects and were safe and Equitable (APEASE criteria), ${ }^{25}$ and prioritised. ${ }^{26}$ Stakeholders (front line and management level nursing, medical and allied health staff) were involved in the assessment of intervention functions during the monthly committee meetings, and a series of meetings where the eHIP concept was tabled at various departmental meetings to garner support for the intervention. Secondly, the authors chose behaviour change techniques (BCTs) from the Behaviour Change Technique Taxonomy (BCTTv1) based on the intervention functions. A BCT is a component of an intervention that will alter behaviour. $^{25}$ The taxonomy includes 93 techniques for behaviour change linked to the Behaviour Change Wheel. Each intervention function is associated with a list of BCTs that are relevant to that intervention function, which can be assessed for relevancy to the local context. For example, if the barriers differed between emergency physicians and surgeons, the intervention function and supporting BCTs were refined to that group. Each BCT was also assessed using the APEASE criteria for inclusion. The resulting BCTs were collated and integrated into an implementation plan approved by the committee and hospital executive.

\section{Results}

Each ACSQHC Hip Fracture Care Clinical Care Standard was mapped to specific actions along with expected outcomes. For example, to operationalise ACSQHC Hip Fracture Care Clinical Care Standard 1: Care at presentation: The triage nurse will identify potential hip fracture patients, order an x-ray and analgesia. "eHIP" page will be activated on confirmation of a hip fracture and activate a series of mandated assessments and treatments (Table 2). These mechanisms were developed into a formal eHIP policy outlining the roles and responsibilities of each team member and a one page flow chart for easy reference (Figure 1).

We identified 83 barriers to the implementation of eHIP in all 14 domains of the TDF. Barriers included concerns about other team members 'I'm completing my step, but what about the others? What if one of the steps is failing? What will be done?" a lack of skills to complete a fascia iliaca block and other assessments not commonly performed by staff. These are all listed in Table 2. These barriers were mapped to nine intervention functions and assessed using the APEASE criteria. The selected 
Table I Barriers to Implementation of eHIP Categorised to the Theoretical Domains Framework

\begin{tabular}{|c|c|}
\hline TDF Domains & Barriers to the Implementation of eHIP Identified by Clinical Staff \\
\hline Knowledge (An awareness of the existence of something) & $\begin{array}{l}\text { What is eHip? } \\
\text { How is it activated and by whom? } \\
\text { How will I know if it's been done, or if I have to do it? } \\
\text { What first, then what etc? le Xrays etc } \\
\text { What pain relief do I use? Why? } \\
\text { How does this affect ortho or med reg referral? } \\
\text { When do we refer to anaesthetics, who, how? } \\
\text { Who will refer to physiotherapy and dietician, when should this be done? } \\
\text { What is the appropriate timeframe for follow up and review? }\end{array}$ \\
\hline Skills (An ability or proficiency acquired through practice) & $\begin{array}{l}\text { How do I actually activate eHIP? } \\
\text { How do I order the x rays online? Do I need special accreditation/access? } \\
\text { How to document analgesia online under the protocol? } \\
\text { How to refer to ortho, anaesthetics, acute pain service, geriatricians, } \\
\text { physiotherapist, dietician? } \\
\text { How to record when the patient has been reviewed by the above teams? } \\
\text { Not many staff know how to perform a Fascia iliac block } \\
\text { For staff from outside the ED, how to find the patient? } \\
\text { How to find and use PAINAD (Pain Assessment in Advanced Dementia (PAINAD) } \\
\text { Scale) })^{37} \text { for pain assessment? } \\
\text { How to perform cognitive assessment? } \\
\text { Which cognitive assessment to use? }\end{array}$ \\
\hline $\begin{array}{l}\text { Social/ Professional Role and Identity (A coherent set of behaviours and } \\
\text { displayed personal qualities of an individual in a social or work setting) }\end{array}$ & $\begin{array}{l}\text { What do I have to do? } \\
\text { Whose job is it to perform various tasks? } \\
\text { Whose job to activate? } \\
\text { Whose job to respond and follow up? } \\
\text { Will I be supported by senior staff to do this role? } \\
\text { What will be my role in this at various stages of the pathway? } \\
\text { How does each individual interact with each other along the pathway, (eg What is } \\
\text { EDs expectations of anaesthetics or physiotherapy? What can I ask of them, when } \\
\text { will I see them?) } \\
\text { What do I tell the staff that do not know about this pathway? }\end{array}$ \\
\hline $\begin{array}{l}\text { Beliefs about Capabilities Self-confidence (Acceptance of the truth, reality, or } \\
\text { validity about an ability, talent, or facility that a person can put to constructive use) }\end{array}$ & $\begin{array}{l}\text { Who do I tell if there is a problem with this system? Will anyone listen? } \\
\text { What else happens on this pathway? } \\
\text { Do I need to do anything differently? } \\
\text { Is it easy to do? } \\
\text { What do I have to tell ortho, geris, anaesthetics? }\end{array}$ \\
\hline $\begin{array}{l}\text { Optimism (The confidence that things will happen for the best or that desired goals } \\
\text { will be attained) }\end{array}$ & $\begin{array}{l}\text { Why bother? } \\
\text { Does it matter when the physio or dietician sees the patient? } \\
\text { Is this just more work for me? } \\
\text { Who does this actually help? } \\
\text { What if I am not told at handover whether eHiP has been activated or not? }\end{array}$ \\
\hline $\begin{array}{l}\text { Beliefs about Consequences (Acceptance of the truth, reality, or validity about } \\
\text { outcomes of a behaviour in a given situation) }\end{array}$ & $\begin{array}{l}\text { How will we know what good and tangible difference will this make for ED flow, } \\
\text { the patient, the ward, and staff? } \\
\text { What happens in each step? What if it does not happen, does everything stop? } \\
\text { Who can I ask about all this stuff? } \\
\text { What if I do it and nothing happens? } \\
\text { What if I do not see any actual benefits in ED of this process? Why keep doing it? }\end{array}$ \\
\hline
\end{tabular}

(Continued) 
Table I (Continued).

\begin{tabular}{|c|c|}
\hline TDF Domains & Barriers to the Implementation of eHIP Identified by Clinical Staff \\
\hline $\begin{array}{l}\text { Reinforcement (Increasing the probability of a response by arranging a dependent } \\
\text { relationship, or contingency, between the response and a given stimulus) }\end{array}$ & $\begin{array}{l}\text { Is anyone going to check that I do it? } \\
\text { What data is being collected and what is being followed up on? What are the } \\
\text { consequences and contingencies that exist at each step? } \\
\text { I am completing my step, but what about the others? What if one of the steps is } \\
\text { failing? What will be done? } \\
\text { Will the hospital support each staff member doing their role? } \\
\text { How do I know if it's working? }\end{array}$ \\
\hline $\begin{array}{l}\text { Intentions (A conscious decision to perform a behaviour or a resolve to act in a certain } \\
\text { way) }\end{array}$ & $\begin{array}{l}\text { How to encourage people to actually do it and remain engaged? } \\
\text { On the wards why continue to involve all the extra staff that keep asking me to do } \\
\text { extra tasks? }\end{array}$ \\
\hline $\begin{array}{l}\text { Goals (Mental representations of outcomes or end states that an individual wants to } \\
\text { achieve) }\end{array}$ & $\begin{array}{l}\text { Who is better off? The staff, the patient, the hospital? } \\
\text { Does it really matter when all this gets done? } \\
\text { How will I know what I have done has achieved something? } \\
\text { What does ordering an xray achieve? } \\
\text { What does referral and review achieve? } \\
\text { Blocks need to be prioritised without impacting care of other patients }\end{array}$ \\
\hline $\begin{array}{l}\text { Memory, Attention and Decision Processes (The ability to retain information, } \\
\text { focus selectively on aspects } \\
\text { of the environment and choose between two or more alternatives) }\end{array}$ & $\begin{array}{l}\text { What if I cannot remember what to do? } \\
\text { How will staff remember to notify and follow the pathway? } \\
\text { How will I remember the individual steps? } \\
\text { If I cannot remember what to do can I find the protocol somewhere? }\end{array}$ \\
\hline $\begin{array}{l}\text { Environmental Context and Resources (Any circumstance of a person's } \\
\text { situation or environment that discourages or encourages the development of skills and } \\
\text { abilities, independence, social competence, and adaptive behaviour) }\end{array}$ & $\begin{array}{l}\text { How to notify? Can I get the clerk to do it? } \\
\text { Will it be easy to access pathway/guidelines? Where do I find this stuff? } \\
\text { I am too busy to do something else } \\
\text { Is there availability of Operating time/staff? } \\
\text { How do I find the patient once activated? } \\
\text { We need availability of equipment to perform procedures, especially FIB (fascia } \\
\text { iliac block) } \\
\text { We need to know staff are available to perform each component } \\
\text { The Cognitive screen needs to be easily available on eMR (electronic medical } \\
\text { record) } \\
\text { Staff to be released for training } \\
\text { Availability of anaesthetic registrar (has several responsibilities including preop } \\
\text { consults, pain round, labour epidurals, cardioversions, arrest. }\end{array}$ \\
\hline $\begin{array}{l}\text { Social influences (Those interpersonal processes that can cause individuals to change } \\
\text { their thoughts, feelings, or behaviours) }\end{array}$ & $\begin{array}{l}\text { Nobody else does it why should I? } \\
\text { I do it and do not see anything happening, people do not do what they are } \\
\text { supposed to } \\
\text { Is it working? } \\
\text { What's my part again? } \\
\text { Do the bosses even care if I do this? }\end{array}$ \\
\hline $\begin{array}{l}\text { Emotion (A complex reaction pattern, involving experiential, behavioural, and } \\
\text { physiological elements, by which the individual attempts to deal with a personally } \\
\text { significant matter or event) }\end{array}$ & $\begin{array}{l}\text { I just cannot do anything else } \\
\text { I am overloaded } \\
\text { We are all doing overtime and can barely do urgent patient care } \\
\text { I am going to end up doing all of these when I am working with <name> } \\
\text { Am I going to have all these doctors hassling me now? I am too busy! } \\
\text { NO more pathways! }\end{array}$ \\
\hline $\begin{array}{l}\text { Behavioural Regulation (Anything aimed at managing or changing objectively } \\
\text { observed or measured actions) }\end{array}$ & $\begin{array}{l}\text { What's the policy? } \\
\text { How do I know if it's working, if everyone is doing it? } \\
\text { How will we know what good and tangible difference will this make for ED flow, } \\
\text { the patient, the ward, and staff? }\end{array}$ \\
\hline
\end{tabular}

Note: TDF domains are emphasised in bold text and described within parentheses italicized. 
Table 2 eHIP Mechanism to Meet Each ACSQHC Hip Fracture Care Clinical Care Standard

\begin{tabular}{|c|c|}
\hline \multicolumn{2}{|c|}{ ACSQHC Hip Fracture Standard I: Care at presentation } \\
\hline $\begin{array}{l}\text { eHIP } \\
\text { intervention }\end{array}$ & $\begin{array}{l}\text { The Emergency Department (ED) triage nurse will identify potential hip fracture patients, order an x-ray and analgesia. "eHIP" } \\
\text { page will be activated on confirmation of a hip fracture and activate a series of mandated assessments and treatments (Figure I). }\end{array}$ \\
\hline $\begin{array}{l}\text { Expected } \\
\text { Outcome }\end{array}$ & $\begin{array}{l}\text { Early recognition and notification enables tailored patient care through a mandated rapid multidisciplinary response within } 60 \\
\text { minutes } 24 / 7 \text {, pain assessment and cognitive screening. Analgesia within } 30 \text { minutes }\end{array}$ \\
\hline \multicolumn{2}{|c|}{ ACSQHC Hip Fracture Standard 2: Pain management } \\
\hline $\begin{array}{l}\text { eHIP } \\
\text { intervention }\end{array}$ & $\begin{array}{l}\text { Nursing staff will document pain assessment as part of routine vital sign collection. Nurses will be empowered to initiate } \\
\text { analgesia, FIBs and pain service referrals. The acute pain service will respond to eHIP page within } 60 \text { minutes } 24 / 7 \text { to facilitate } \\
\text { daily assessment/review. }\end{array}$ \\
\hline $\begin{array}{l}\text { Expected } \\
\text { Outcome }\end{array}$ & $\begin{array}{l}\text { Recognition of analgesic needs at presentation and throughout hospital stay. Initiation and monitoring of effective and timely } \\
\text { multimodal analgesia throughout patient's hospital stay to enable early mobilisation }\end{array}$ \\
\hline \multicolumn{2}{|c|}{ ACSQHC Hip Fracture Standard 3: Orthogeriatric model of care } \\
\hline $\begin{array}{l}\text { eHIP } \\
\text { intervention }\end{array}$ & $\begin{array}{l}\text { Orthogeriatrics are part of the eHIP notification page and are aware of their initial and ongoing responsibilities including a daily } \\
\text { consult service. }\end{array}$ \\
\hline $\begin{array}{l}\text { Expected } \\
\text { Outcome }\end{array}$ & $\begin{array}{l}\text { Orthogeriatric assessment in ED then ongoing coordination of needs including reassessment of cognition after surgery, } \\
\text { discharge planning, falls and secondary fracture prevention. }\end{array}$ \\
\hline \multicolumn{2}{|c|}{ ACSQHC Hip Fracture Standard 4: Timing of surgery (<48hrs) } \\
\hline $\begin{array}{l}\text { eHIP } \\
\text { intervention }\end{array}$ & $\begin{array}{l}\text { Orthopaedic, anaesthetic, geriatric teams and bed manager will be notified when patient at triage. Will review patient within } 60 \\
\text { minutes and expedite assessment and booking of operative intervention - replacing multiple, sequential delayed phone calls. } \\
\text { Patients requiring transfer from SDMH to WH will not require repeat Anaesthetic consult and will be booked directly to the } \\
\text { operative list }\end{array}$ \\
\hline $\begin{array}{l}\text { Expected } \\
\text { Outcome }\end{array}$ & $\begin{array}{l}\text { Early notification, inter-hospital transfer (if required), booking of operative intervention and risk screens to enable surgery } \\
<48 \mathrm{hrs.}\end{array}$ \\
\hline \multicolumn{2}{|c|}{ ACSQHC Hip Fracture Standard 5: Day I Mobilisation and weight-bearing } \\
\hline $\begin{array}{l}\text { eHIP } \\
\text { intervention }\end{array}$ & $\begin{array}{l}\text { Automated referral to physiotherapy } 7 \text { days/week. Post-op patient prioritised. Physiotherapy team aware of need and } \\
\text { empowered for day I mobilisation }\end{array}$ \\
\hline $\begin{array}{l}\text { Expected } \\
\text { Outcome }\end{array}$ & $\begin{array}{l}\text { Gold standard pain management, and recommended falls and delirium assessments will already have been completed so safe } \\
\text { mobilisation can be imitated the day after hip fracture surgery unless contraindicated. }\end{array}$ \\
\hline \multicolumn{2}{|c|}{ ACSQHC Hip Fracture Standard 6: Minimising risk of another fracture } \\
\hline $\begin{array}{l}\text { eHIP } \\
\text { intervention }\end{array}$ & $\begin{array}{l}\text { Falls and bone health assessments/plans including bone protection medication will be part of eHIP. The nurse manager of each } \\
\text { ward, along with the aged care nurse consultant will be empowered to ensure each ACSQHC Standard occurs, facilitated via } \\
\text { a daily ward round that assesses eHIP compliance. This round includes early authentic carer engagement and shared decision } \\
\text { making. }\end{array}$ \\
\hline $\begin{array}{l}\text { Expected } \\
\text { Outcome }\end{array}$ & $\begin{array}{l}\text { Tailored patient education on and intervention for risk factors for falls conducted by aged care nurse consultant and } \\
\text { physiotherapy. }\end{array}$ \\
\hline \multicolumn{2}{|c|}{ ACSQHC Hip Fracture Standard 7: Transition from hospital care } \\
\hline $\begin{array}{l}\text { eHIP } \\
\text { intervention }\end{array}$ & $\begin{array}{l}\text { Optimised by the commencement of an individualised care plan early in the hospital stay by the orthogeriatric multidisciplinary } \\
\text { team. A template will be developed to ensure a clear description of the patient's ongoing care and goals following discharge. } \\
\text { This includes collaboration with and "handover" to GP. }\end{array}$ \\
\hline $\begin{array}{l}\text { Expected } \\
\text { Outcome }\end{array}$ & Consistent, reliable and streamlined "handover" to the patient's GP \\
\hline
\end{tabular}

Note: ACSQHC hip fracture standards are italicized. 


\section{Hip Fracture Pathway - Notification and Management of Hip Fracture (eHIP)}

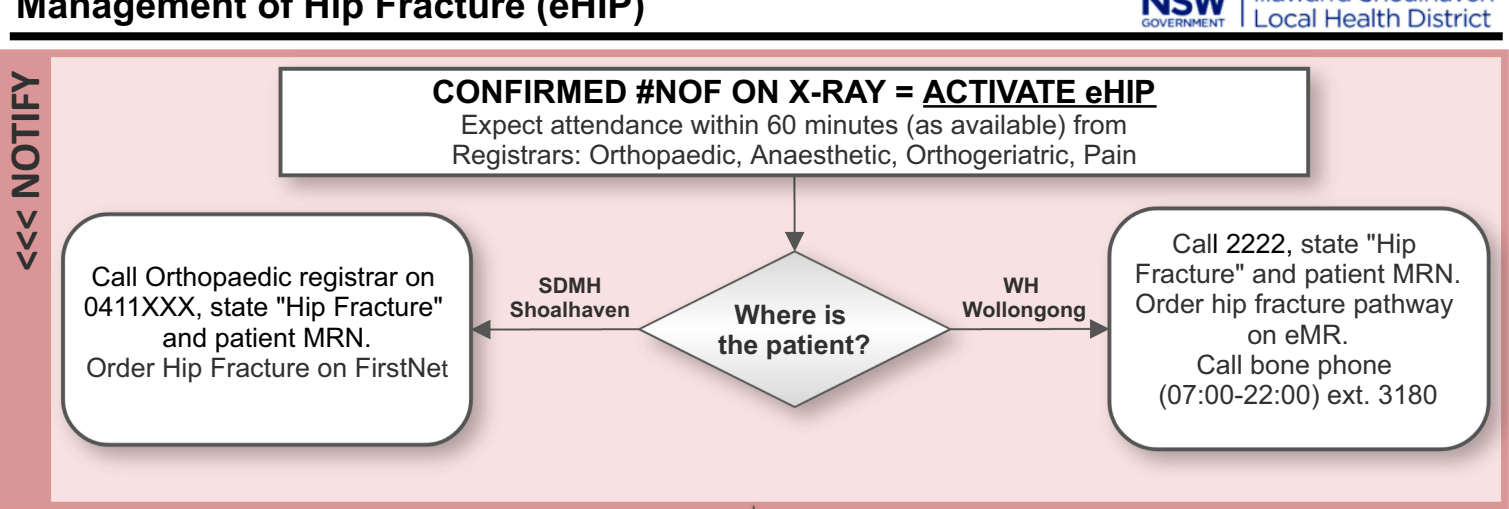

\section{START EHIP FRACTURE CARE BUNDLE AND PATHWAY DOCUMENTATION}
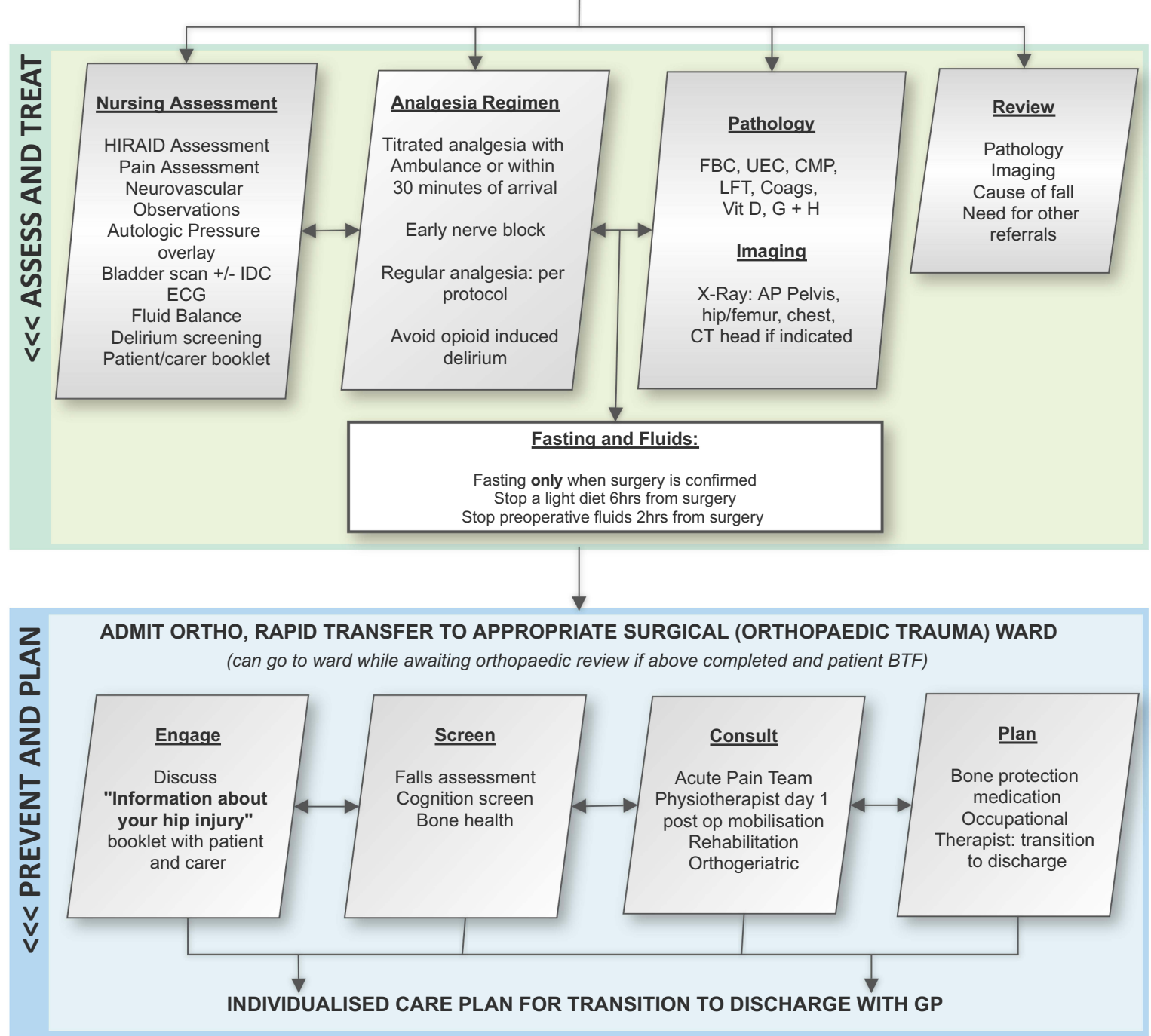

Figure I Flow chart summarising the eHIP policy and process. Red, green, and blue sections represent the notify, assess and treat, and plan and prevent stages of eHIP, respectively.

Abbreviations: \#NOF, neck of femur fracture; SDMH, Shoalhaven District Memorial Hospital; WH, Wollongong Hospital; MRN, medical record number; eMR, electronic medical record; HIRAD, history, red flags, assessment, intervention, diagnostics; IDC, indwelling catheter; ECG, electrocardiograph; FBC, full blood count; UEC, urea, electrolytes, creatinine; CMP, calcium, magnesium, phosphate; LFT, liver function tests; Vit D, vitamin (D); G + H, group and hold; BTF, vital signs between the flags; GP, general practitioner. 
intervention functions were mapped to BCTTs. The 41 BCTTs selected by the committee and stakeholders during the consultation process were mechanised through operational changes to electronic medical records (eMR), a communication plan, an informative and instructional video (Supplementary Video 1, Figure 2), monitoring by clinical champions, additional training in procedures and assessment skills, and clear delineation in expectations of individual staff members (Table 3). eHIP went live on 22nd of June, 2020.

\section{Discussion}

This paper describes the development and implementation of a care bundle called eHIP to operationalise the ACSQHC Hip Fracture Care Clinical Care Standard. The development of eHIP and its supporting policy was relatively straightforward, due to existing national guidelines and the support of clinicians with the opportunity and motivation to initiate and coordinate change. However, navigating the organisational barriers for the vulnerable hip fracture patient group was complex.

For eHIP to have a high chance of sustainable success, our strategy needed to consider clinician behavior change, organizational resources and culture. ${ }^{29}$ This is not a unique finding. ${ }^{18,30}$ Implementing change in health care is an inherently political process influenced by prevailing power structures, clinician behavior, ${ }^{19}$ lack of time, individual motivation and the culture of specific healthcare discipline. ${ }^{27,28}$ Implementation needs planning and strategies that address the complexity of healthcare systems, individual practitioners, managers, as well as strong organizational support and patronage which is influential to normalize a new practice among staff. ${ }^{19,31,32}$ We achieved this through application of the behavior change wheel, ${ }^{25}$ as have colleagues elsewhere. ${ }^{30,33}$

Despite a robust implementation plan and strategy to address all the well-known barriers to change, our implementation was not immune, particularly amid a global pandemic and the subsequent competing priorities among various crucial stakeholders, such as the

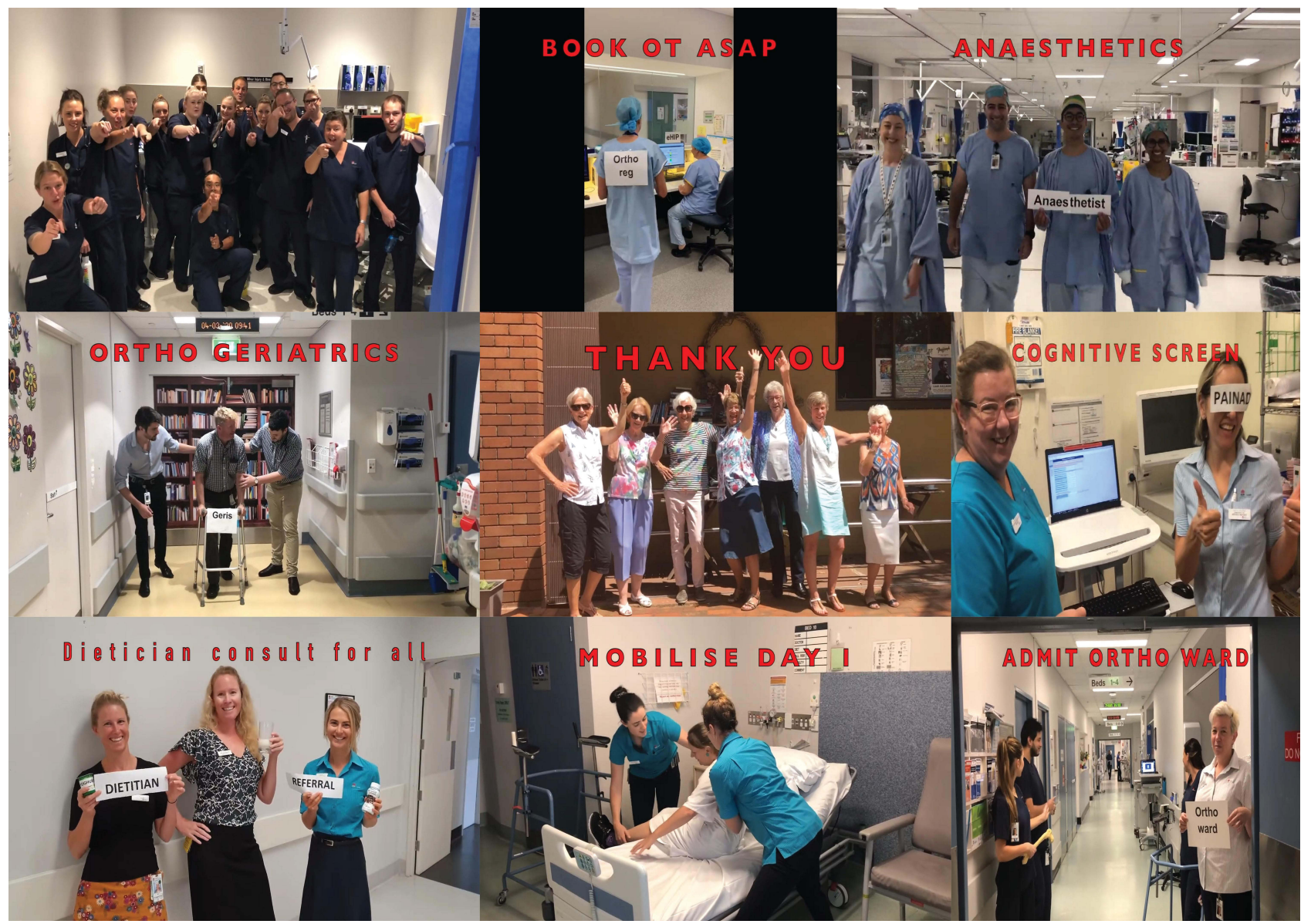

Figure 2 Screen shots from eHIP implementation video. 
Table 3 Mechanism, Intervention Functions, and Behavioural Change Technique Taxonomy (BCTT) as Identified Using the Behaviour Change Wheel

\begin{tabular}{|c|c|c|}
\hline Mechanism & $\begin{array}{l}\text { Intervention } \\
\text { Functions }\end{array}$ & BCTTs \\
\hline Formal policy that outlines eHIP roles & $\begin{array}{l}\text { Incentivisation } \\
\text { Restriction } \\
\text { Enablement }\end{array}$ & $\begin{array}{l}\text { Goals and planning } \\
\text { I.4 Action planning } \\
\text { Feedback and monitoring } \\
2.3 \text { Self-monitoring of behaviour } \\
\text { Shaping knowledge } \\
\text { 4.I. Instruction on how to pe } \\
\text { form the behaviour } \\
\text { Associations } \\
\text { 7.I Prompts/cues } \\
\text { Covert learning } \\
\text { 16.I. Imaginary punishment }\end{array}$ \\
\hline $\begin{array}{l}\text { Video-Promo: of ehip process, expected behaviours, benefits, roles re } \\
\text { activation and response. Use senior staff with credibility to model and } \\
\text { reinforce, use frontliners for social influence. Make fun, short and easy to } \\
\text { watch to emphasise ease and minimal changes. Enhance with music } \\
\text { (Supplementary Video I). }\end{array}$ & $\begin{array}{l}\text { Education } \\
\text { Persuasion } \\
\text { Incentivisation } \\
\text { Training } \\
\text { Modelling } \\
\text { Enablement }\end{array}$ & $\begin{array}{l}\text { Goals and planning } \\
\text { I.4. Action planning } \\
\text { 1.5. Review behaviour goal(s) } \\
\text { 1.7. Review outcome goal(s) } \\
\text { Shaping knowledge } \\
\text { 4.I. Instruction on how to perform the behaviour } \\
\text { Natural consequences } \\
\text { 5.I. Information about health consequences } \\
\text { Comparison of behaviour } \\
\text { 6.I. Demonstration of the behaviour } \\
\text { 6.2. Social comparison } \\
\text { 6.3. Information about others' approval } \\
\text { Associations } \\
\text { 7.8. Associative learning } \\
\text { Reward and threat } \\
\text { 10.4. Social reward } \\
\text { 10.5. Social incentive } \\
\text { Self-belief } \\
\text { 15.I. Verbal persuasion about capability }\end{array}$ \\
\hline $\begin{array}{l}\text { Pager group: Meetings with multiple stakeholders to discuss methods of } \\
\text { communication with appropriate staff. Setting up pagers or eMR based } \\
\text { communication and responses. Discussing expected response to the page or } \\
\text { communication. }\end{array}$ & $\begin{array}{l}\text { Persuasion } \\
\text { Incentivisation/ } \\
\text { Coercion } \\
\text { Restriction } \\
\text { Environmental } \\
\text { restructuring } \\
\text { Enablement }\end{array}$ & $\begin{array}{l}\text { Feedback and monitoring } \\
\text { 2.I. Monitoring of behaviour by others without feedback } \\
\text { 2.3. Self-monitoring of behaviour } \\
\text { Associations } \\
\text { 7.I. Prompts/cues }\end{array}$ \\
\hline $\begin{array}{l}\text { Fascia lliaca Block enabling } \\
\text { Expansion of training to nurses, easier access to equipment. Encouragement } \\
\text { and exposure to technique and benefits. Introduction of analgesia policy, } \\
\text { decreasing use of other analgesics to favour this method } \\
\text { Training in FIB, Ultrasound, education program obtained from NSW ACI, FIB } \\
\text { box } \\
\text { Special area for FIB catheters }\end{array}$ & $\begin{array}{l}\text { Education } \\
\text { Training } \\
\text { Restriction } \\
\text { Environmental } \\
\text { restructuring } \\
\text { Enablement }\end{array}$ & $\begin{array}{l}\text { Shaping knowledge } \\
\text { 4.I. Instruction on how to perform the behaviour } \\
\text { Social support } \\
\text { 3.2. Social support (practical) } \\
\text { Comparison of outcomes } \\
\text { 9.1. Credible source } \\
\text { Antecedents } \\
\text { 12.2. Restructuring the social } \\
\text { Environment } \\
\text { Self-belief } \\
\text { 15.I. Verbal persuasion about capability }\end{array}$ \\
\hline
\end{tabular}

(Continued) 
Table 3 (Continued).

\begin{tabular}{|c|c|c|}
\hline Mechanism & $\begin{array}{l}\text { Intervention } \\
\text { Functions }\end{array}$ & BCTTs \\
\hline $\begin{array}{l}\text { eMR modifications } \\
\text { Set up of electronic notification package, order set for xrays and analgesia. } \\
\text { Information on steps in pathway. Notification symbol. } \\
\text { Order set for hip fracture blood order set, referral/consult } \\
\text { Icon visible on eMR to reflect activation }\end{array}$ & $\begin{array}{l}\text { Persuasion } \\
\text { Restriction } \\
\text { Environmental } \\
\text { restructuring } \\
\text { Enablement }\end{array}$ & $\begin{array}{l}\text { Goals and planning } \\
\text { 1.7. Review outcome goal(s) } \\
\text { Feedback and monitoring } \\
\text { 2.1. Monitoring of behaviour by others without feedback } \\
\text { 2.2. Feedback on behaviour } \\
\text { 2.3. Self-monitoring of behaviour } \\
\text { 2.4. Self-monitoring of outcome(s) of behaviour } \\
\text { 2.5. Monitoring of outcome(s) of behaviour without feedback } \\
\text { 2.7. Feedback on outcome(s) of behaviour } \\
\text { Natural consequences } \\
\text { 5.5. Anticipated regret } \\
\text { Associations } \\
\text { 7.1. Prompts/cues } \\
\text { Reward and threat } \\
\text { 10.3. Non-specific reward } \\
\text { 10.4. Social reward } \\
\text { 10.5. Social incentive } \\
\text { Covert learning } \\
\text { 16.1. Imaginary punishment } \\
\text { 16.2. Imaginary reward } \\
\text { 16.3. Vicarious consequences }\end{array}$ \\
\hline $\begin{array}{l}\text { F2F formal and informal education that incorporates surgical and ED } \\
\text { orientation processes, surgical grand rounds, regular ED education calendar. } \\
\text { Initially: Info re consequences-health, social and environmental ie what } \\
\text { happens when we follow this process, what happens to the patient when we } \\
\text { follow this process. Info re roles, response, policy, components } \\
\text { Instruction on HOW to perform tasks } \\
\text { Environment-ie FIB box, procedure room } \\
\text { Acknowledge complexity of patients and outcomes } \\
\text { Subsequent: Feedback on performance, behaviour, and outcomes. Reminder } \\
\text { of consequences }\end{array}$ & $\begin{array}{l}\text { Education } \\
\text { Persuasion } \\
\text { Training } \\
\text { Modelling }\end{array}$ & $\begin{array}{l}\text { Goals and planning } \\
\text { I.I.Goal setting (behaviour) } \\
\text { 1.9. Commitment } \\
\text { Shaping knowledge } \\
\text { 4.I. Instruction on how to perform the behaviour } \\
\text { 4.2. Information about Antecedents } \\
\text { Natural consequences } \\
\text { 5.I. Information about health consequences } \\
\text { 5.2. Salience of consequences } \\
\text { Comparison of outcomes } \\
\text { 9.1. Credible source } \\
\text { 9.2. Pros and cons } \\
\text { 9.3. Comparative imagining of future outcomes } \\
\text { Self-belief } \\
\text { 15.I. Verbal persuasion about capability } \\
\text { 15.2. Mental rehearsal of successful performance } \\
\text { 15.3. Focus on past success } \\
\text { 15.4. Self-talk }\end{array}$ \\
\hline $\begin{array}{l}\text { Communication and prompts } \\
\text { Short Comms (Posters, emails) } \\
\text { Emails sent to each speciality head of department and distributed to staff } \\
\text { about specific role, included link to video and protocol } \\
\text { Newsletter item for ED, surgery } \\
\text { SMIT (ED): short, snappy that includes } \\
\text { Info consequences-for pt, for staff } \\
\text { Roles and responsibilities } \\
\text { How to activate } \\
\text { Include info from credible sources ie CE, NUM etc }\end{array}$ & $\begin{array}{l}\text { Education } \\
\text { Persuasion } \\
\text { Environmental } \\
\text { restructuring } \\
\text { Modelling } \\
\text { Enablement }\end{array}$ & $\begin{array}{l}\text { Goals and planning } \\
\text { 1.8. Behavioural contract } \\
\text { 1.9. Commitment } \\
\text { Feedback and monitoring } \\
\text { 2.2. Feedback on behaviour } \\
\text { Social support } \\
\text { 3.3. Social support (emotional) } \\
\text { Comparison of behaviour } \\
\text { 6.3. Information about others' approval } \\
\text { Associations } \\
\text { 7.1. Prompts/cues } \\
\text { Repetition and substitution } \\
\text { 8.6. Generalisation of target behaviour } \\
\text { Reward and threat } \\
\text { 10.4. Social reward } \\
\text { 10.5. Social incentive }\end{array}$ \\
\hline
\end{tabular}

(Continued) 
Table 3 (Continued).

\begin{tabular}{|c|c|c|}
\hline Mechanism & $\begin{array}{l}\text { Intervention } \\
\text { Functions }\end{array}$ & BCTTs \\
\hline $\begin{array}{l}\text { Face to face reinforcement and modelling by clinical leaders. An } \\
\text { implementation nurse was employed for } 3 \text { months to follow the patient } \\
\text { journey and ensure implementation of each component. The leaders } \\
\text { provided feedback on behaviour and patient outcomes, demonstrated best } \\
\text { practice, and escalated problems to the relevant departmental managers as } \\
\text { needed. }\end{array}$ & $\begin{array}{l}\text { Education } \\
\text { Persuasion } \\
\text { Training } \\
\text { Restriction } \\
\text { Modelling }\end{array}$ & $\begin{array}{l}\text { Goals and planning } \\
\text { I.6. Discrepancy between current behaviour and goal } \\
\text { I.8. Behavioural contract } \\
\text { I.9. Commitment } \\
\text { Feedback and monitoring } \\
\text { 2.1. Monitoring of behaviour by others without feedback } \\
\text { 2.2. Feedback on behaviour } \\
\text { Social support } \\
\text { 3.I. Social support (unspecified) } \\
\text { 3.2. Social support (practical) } \\
\text { 3.3. Social support (emotional) } \\
\text { Shaping knowledge } \\
\text { 4.I. Instruction on how to perform the behaviour } \\
\text { 4.2. Information about Antecedents } \\
\text { Associations } \\
\text { 7.I. Prompts/cues }\end{array}$ \\
\hline $\begin{array}{l}\text { Environmental restructuring that included the generation of a dedicated } \\
\text { box containing equipment to perform a FIB. Access to a dedicated } \\
\text { anaesthetics procedure room for blocks or insertion of regional anaesthesia } \\
\text { catheters if the patient is on the ward awaiting surgery. }\end{array}$ & $\begin{array}{l}\text { Environmental } \\
\text { Training } \\
\text { Restriction } \\
\text { Modelling } \\
\text { Enablement }\end{array}$ & $\begin{array}{l}\text { Goals and planning } \\
\text { I.4. Action planning } \\
\text { Social support } \\
\text { 3.1. Social support (unspecified) } \\
\text { Shaping knowledge } \\
\text { 4.I. Instruction on how to perform the behaviour } \\
\text { 4.2. Information about Antecedents } \\
\text { Comparison of behaviour } \\
\text { 6.3. Information about others' approval } \\
\text { Associations } \\
\text { 7.7. Exposure } \\
\text { Comparison of outcomes } \\
\text { 9.1. Credible source } \\
\text { 9.2. Pros and cons } \\
\text { 9.3. Comparative imagining of future outcomes } \\
\text { Self-belief } \\
\text { 15.I. Verbal persuasion about capability }\end{array}$ \\
\hline $\begin{array}{l}\text { Reporting to end users } \\
\text { Data collection processes refined, consolidated to enable reporting locally } \\
\text { and to the ANZHFR. } \\
\text { Implementation evaluation planned to measure patient and health service } \\
\text { outcomes. }\end{array}$ & $\begin{array}{l}\text { Education } \\
\text { Persuasion } \\
\text { Incentivisation } \\
\text { Coercion }\end{array}$ & $\begin{array}{l}\text { Goals and planning } \\
\text { I.6. Discrepancy between current behaviour and goal } \\
\text { Feedback and monitoring } \\
\text { 2.1. Monitoring of behaviour by others without feedback } \\
\text { 2.2. Feedback on behaviour } \\
\text { 2.7. Feedback on outcome(s) of behaviour } \\
\text { Associations } \\
\text { 7.1. Prompts/cues } \\
\text { 7.7. Exposure } \\
\text { 7.8. Associative learning } \\
\text { Reward and threat } \\
\text { 10.3. Non-specific reward }\end{array}$ \\
\hline
\end{tabular}

Note: Numbering within the "BCTT" column presents the BCTT in their hierarchical order described by Michie et al under their respective category in bold.

electronic medical record team. This impacted crucial aspects of the implementation (changes to the electronic notification and referral processes) and made regular well-attended committee meetings challenging, given many staff had leadership roles within our organization's response to COVID-19.
Implementation of a new process involves many processes, systems and interactions. ${ }^{34}$ In our complex and multidisciplinary healthcare system, aside from our patients, who are at the center of care, those impacted by eHIP included multiple services and medical specialties from outside of the instigating departments, such as the 
hospital switchboard, radiology, allied health and hospital executive. We managed to reach agreement among diverse and multiple stakeholders with differing priorities by considering valuing the skills and knowledge of each discipline in the micropolitical context of the health service. ${ }^{19}$ We also gained support across multiple levels of leadership. ${ }^{19}$ It is critical to involve end users throughout the process, which we did by establishing a working party of key stakeholders to develop a consensus plan to streamline implementation.

The next stages of our eHIP project will include evaluation of the clinical efficacy of eHIP, as well as measurement of "reach", "fidelity", and "dose". 35 Reach assesses whether the intended recipients came into contact with an intervention, this is, how many hip fracture patients received an eHIP activation and if it was appropriate. ${ }^{35}$ Fidelity will assess if eHIP was delivered as intended and if adaptations were made. Dose will evaluate the quantity of the intervention implemented, that is, each component of the ACSQHC Hip Fracture Care Clinical Care Standard. ${ }^{35,36}$

\section{Conclusion}

The implementation of any intervention in the complex acute care environment requires consideration of local micropolitics and influencers on individual and collective human behaviour. We applied behaviour change theory through a pragmatic evidence-based process. This resulted in a codesigned strategy to overcome staff and organisational barriers to the implementation of a multidisciplinary early activation mechanism and bundle of care (eHIP). Future work will include evaluation of the uptake and clinical impact of the care bundle.

\section{Acknowledgments}

NSW Agency for Clinical Innovation and Illawarra Health and Medical Research Institute for funding.

\section{Disclosure}

The authors declare that they have no known competing financial interests or personal relationships that could have appeared to influence the work reported in this paper.

\section{References}

1. Goh EL, Lerner RG, Achten J, Parsons N, Griffin XL, Costa PML. Complications following hip fracture: results from the World Hip Trauma Evaluation cohort study. Injury. 2020;51(6):1331-1336. doi:10.1016/j.injury.2020.03.031
2. Dixon T. The Problem of Osteoporotic Hip Fracture in Australia. Canberra: AIHW; 2010.

3. Health AIo, Welfare. Estimating the Prevalence of Osteoporosis in Australia. Canberra: AIHW; 2014.

4. Health AIo, Welfare. Australia's Hospitals at a Glance 2016-17. Canberra: AIHW; 2018.

5. Watts JJ, Abimanyi-Ochom J, Sanders KM. Osteoporosis Costing All Australians: A New Burden of Disease Analysis - 2012 to 2022. Sydney: Osteoporosis Australia; 2013.

6. Buse GL, Mohit B, Sancheti P, et al. Accelerated care versus standard care among patients with hip fracture: the HIP ATTACK pilot trial. Can Med Assoc J. 2014;186(1):E52.

7. Panella M, Seys D, Sermeus W, et al. Minimal impact of a care pathway for geriatric hip fracture patients. Injury. 2018;49 (8):1581-1586. doi:10.1016/j.injury.2018.06.005

8. National Institute for Health and Care Excellence. Hip fracture: management clinical guideline [CG124]; 2017.

9. Or O, Fisher Negev T, Hadad V, et al. Fracture liaison service for hip fractures: is it a game changer? IMAJ. 2021;23(8):490-493.

10. Costa ML, Griffin XL, Achten J, et al. World Hip Trauma Evaluation (WHiTE): framework for embedded comprehensive cohort studies. BMJ Open. 2016;6(10):e011679. doi:10.1136/bmjopen-2016-011679

11. ACSQHC. Hip Fracture Care Clinical Care Standard. Sydney: ACSQHC; 2016.

12. ANZHFR. Bi-national annual report of hip fracture care; 2020.

13. Chuan A, Zhao L, Tillekeratne N, et al. The effect of a multidisciplinary care bundle on the incidence of delirium after hip fracture surgery: a quality improvement study. Anaesthesia. 2020;75(1):63-71. doi:10.1111/anae.14840

14. Cehic M, Lerner RG, Achten J, Griffin XL, Prieto-Alhambra D, Costa ML. Prescribing and adherence to bone protection medications following hip fracture in the United Kingdom. Bone Joint J. 2019;101-B(11):1402-1407. doi:10.1302/0301-620X.101B11.BJJ2019-0387.R1

15. Lian T, Dybvik E, Gjertsen J-E, et al. Compliance with national guidelines for antibiotic prophylaxis in hip fracture patients: a quality assessment study of 13329 patients in the Norwegian Hip Fracture Register. BMJ Open. 2020;10(5):e035598. doi:10.1136/ bmjopen-2019-035598

16. Schulze Raestrup U, Grams A, Smektala R. Guideline compliance in hip fracture: results of an external quality-assurance program in North Rhine Westphalia: 2003-2005. Der Unfallchirurg. 2008;111 (2):65-70. doi:10.1007/s00113-008-1405-0

17. Zielinski S, Meeuwis MA, Heetveld M, et al. Adherence to a femoral neck fracture treatment guideline. Int Orthop. 2013;37(7):1327-1334. doi:10.1007/s00264-013-1888-3

18. Rath S, Yadav L, Tewari A, et al. Management of older adults with hip fractures in India: a mixed methods study of current practice, barriers and facilitators, with recommendations to improve care pathways. Arch Osteoporos. 2017;12(1):55. doi:10.1007/s11657-017-0344-1

19. Rogers L, De Brún A, Birken SA, Davies C, McAuliffe E. The micropolitics of implementation; a qualitative study exploring the impact of power, authority, and influence when implementing change in healthcare teams. BMC Health Serv Res. 2020;20(1):1059. doi:10.1186/s12913-020-05905-z

20. ANZHFR. Bi-national annual report of hip fracture care; 2019.

21. ANZHFR. Bi-national annual report of hip fracture care; 2018.

22. Atkins L, Francis J, Islam R, et al. A guide to using the theoretical domains framework of behaviour change to investigate implementation problems. Implement Sci. 2017;12(1):77. doi:10.1186/s13012017-0605-9

23. French SD, Green SE, O'Connor DA, et al. Developing theory-informed behaviour change interventions to implement evidence into practice: a systematic approach using the theoretical domains framework. Implement Sci. 2012;7:38. doi:10.1186/17485908-7-38 
24. Bennetts S, Campbell-Brophy E, Huckson S, Doherty S, National H. Medical research council's national institute for clinical studies national emergency care pain management I. Pain management in Australian emergency departments: current practice, enablers, barriers and future directions. Emergency Med Australasia. 2012;24 (2):136-143. doi:10.1111/j.1742-6723.2011.01499.x

25. Michie S, Atkins L, West R. The Behaviour Change Wheel: A Guide to Designing Interventions. Great Britain: Silverback Publishing; 2014.

26. Sinnott C, Mercer SW, Payne RA, Duerden M, Bradley CP, Byrne M. Improving medication management in multimorbidity: development of the MultimorbiditY COllaborative Medication Review And DEcision Making (MY COMRADE) intervention using the behaviour change wheel. Implementation Sci. 2015;10(1):132. doi:10.1186/s13012-015-0322-1

27. Handley MA, Gorukanti A, Cattamanchi A. Strategies for implementing implementation science: a methodological overview. Emergency Med J. 2016;33(9):660. doi:10.1136/emermed-2015205461

28. Jabbour M, Newton AS, Johnson D, Curran JA. Defining barriers and enablers for clinical pathway implementation in complex clinical settings. Implement Sci. 2018;13(1):139. doi:10.1186/s13012-0180832-8

29. Glisson $\mathrm{C}$. The role of organizational culture and climate in innovation and effectiveness. Human Serv Organ. 2015;39(4):245-250.

30. Oberai T, Laver K, Killington M, Woodman R, Crotty M, Jaarsma R. No longer lost in translation: study protocol for preventing delirium post hip fracture. Eur J Pers Centered Healthcare. 2019;7:98-105.
31. Resnick LA. Paving clinical pathways: using a trusted change management model to establish standardized, evidence-based care across the continuum. ASQ's Healthcare Update; 2014.

32. Seckler E, Regauer V, Rotter T, Bauer P, Müller M. Barriers to and facilitators of the implementation of multi-disciplinary care pathways in primary care: a systematic review. BMC Fam Pract. 2020;21 (1):113. doi:10.1186/s12875-020-01179-w

33. Thomas S, Mackintosh S. Use of the theoretical domains framework to develop an intervention to improve physical therapist management of the risk of falls after discharge. Phys Ther. 2014;94 (11):1660-1675. doi:10.2522/ptj.20130412

34. Curtis K, Fry M, Shaban RZ, Considine J. Translating research findings to clinical nursing practice. J Clin Nurs. 2017;26(56):862-872. doi:10.1111/jocn.13586

35. Moore GF, Audrey S, Barker M, et al. Process evaluation of complex interventions: medical Research Council guidance. BMJ. 2015;350: h1258. doi:10.1136/bmj.h1258

36. Carroll C, Patterson M, Wood S, Booth A, Rick J, Balain S. A conceptual framework for implementation fidelity. Implementation Sci. 2007;2(1):40. doi:10.1186/1748-5908-2-40

37. Warden V, Hurley AC, Volicer L. Development and Psychometric Evaluation of the Pain Assessment in Advanced Dementia (PAINAD) scale. J Am Med Dir Assoc. 2003;4(1):9-15. doi:10.1097/01. JAM.0000043422.31640.F7
Journal of Multidisciplinary Healthcare

\section{Publish your work in this journal}

The Journal of Multidisciplinary Healthcare is an international, peerreviewed open-access journal that aims to represent and publish research in healthcare areas delivered by practitioners of different disciplines. This includes studies and reviews conducted by multidisciplinary teams as well as research which evaluates the results or conduct of such teams or healthcare processes in general. The journal

\section{Dovepress}

covers a very wide range of areas and welcomes submissions from practitioners at all levels, from all over the world. The manuscript management system is completely online and includes a very quick and fair peer-review system. Visit http://www.dovepress.com/testimonials. php to read real quotes from published authors. 